\title{
A GENERALIZATION OF CONTRACTION PRINCIPLE
}

\author{
K.M. GHOSH \\ Dept. of Pure Mathematics \\ Calcutta University \\ 35, Ballygunge Circular Road \\ Calcutta - 700019 \\ INDIA
}

(Received December 6, 1979 and in revised form April 21, 1980)

ABSTRACT: In this paper, a generalized mean value contraction is introduced.

This contraction is an extension of the contractions of earlier researchers and of the generalized mean value non-expansive mapping. Using the generalized mean value contraction, some fixed point theorems are discussed. KEY WORDS AND PHRASES: Fixed Point, Mean Value Iteration. 1980 MATHEMATICS SUBJECT CLASSIFICATION CODES: Primary 47 H10

1. INTRODUCTION.

Let $\mathrm{T}$ be a self mapping of a Banach space $\mathrm{E}$. The mapping $\mathrm{T}$ will be called a generalized mean value contraction mapping if for any $x, y \in E$, there exist non-negative real numbers $a_{i}(i=1,2, \ldots 5)$ such that || $\mathrm{TT}_{\lambda} \mathrm{x}-\mathrm{TT}_{\lambda} \mathrm{y}\left|\underline{\leq}_{1} \mathrm{a}_{1}\right||\mathrm{x}-\mathrm{y}|\left|+\mathrm{a}_{2}\right|\left|\mathrm{x}-\mathrm{TT}_{\lambda} \mathrm{x}\right|\left|+\mathrm{a}_{3}\right|\left|\mathrm{y}-\mathrm{TT} \lambda_{\lambda} \mathrm{y}\right|+\mathrm{a}_{4}|| \mathrm{x}-\mathrm{TT} \mathrm{T}_{\lambda}||+\mathrm{a}_{5}|| \mathrm{y}-\mathrm{TT} \mathrm{x}||$ where $\sum_{i=1}^{5} \mathrm{a}_{i}<1$ and $\mathrm{T}_{\lambda} \mathrm{x}=\lambda \mathrm{x}+(1-\lambda) \mathrm{Tx}$, and $\mathrm{TT}_{\lambda} \mathrm{x}=\mathrm{T}(\lambda \mathrm{x}+(1-\lambda) \mathrm{Tx}), 0<\lambda \leq 1$ holds The contraction (1.1) is more general than the Banach contraction, contractions of 
Kannan [1], Chatterjee [2], Hardy and Rogers [3]. When $\lambda=1$ all these contractions follow as a particular case of (1.1), with suitable choice of $a_{i}$ 's. Also, by example, we show that there exist self-mappings which satisfy (1.1), but do not satisfy the well-known contraction just mentioned.

EXAMPLE 1. Let $T$ be a self-mapping on $[0,1]$ defined by

$$
\mathrm{T}(0)=1, \mathrm{~T}(1)=0, \mathrm{~T}(\mathrm{x})=\frac{1}{9}, \mathrm{x} \in(0,1) \text {. }
$$

EXAMPLE 2. Let $T$ be a self-mapping on $[0,1]$ defined by $T(x)=1-x, x \in[0,1]$. EXAMPLE 3. Let $T$ be a self-mapping on $[-1,1]$ defined by $T x=-x, x \in[-1,1]$.

The mapping $\mathrm{T}$ of the above examples satisfies (1.1) for $\lambda=\frac{1}{2}$. However, for $x=0, y=1, T$ of Example 1 or Example 2, and for $x=1, y=-1, T$ of Example 3 do not satisfy the above well-known contractions. Next, we define generalized mean value non-expansive mapping: Let $\mathrm{T}$ be a self-mapping of a Banach space $\mathrm{E}$. Then $\mathrm{T}$ will be called a generalized mean value non-expansive mapping if for any $x, y$ in $E$, there exists non-negative real numbers $a_{i}(i=1,2, \ldots 5)$ such that

$$
|| \operatorname{TT}_{\lambda} \mathrm{x}-\mathrm{TT}_{\lambda} \mathrm{y}|| \leq \mathrm{a}_{1}|| \mathrm{x}-\mathrm{y}||+\mathrm{a}_{2}|| \mathrm{x}-\mathrm{TT}_{\lambda} \mathrm{x}||+\mathrm{a}_{3}|| \mathrm{y}-\mathrm{TT}_{\lambda} \mathrm{y} \|+\mathrm{a}_{4}|| \mathrm{x}-\mathrm{TT}_{\lambda} \mathrm{y}||+\mathrm{a}_{5}|| \mathrm{y}-\mathrm{TT} \lambda_{\lambda} \mathrm{x}|| \text {, }
$$

where $\sum_{i=1}^{5} \mathrm{a}_{i}=1$ and $\mathrm{T}_{\lambda} \mathrm{x}=\lambda \mathrm{x}+(1-\lambda) \mathrm{Tx}, 0<\lambda \leq 1$ holds.

Now we define a new contraction which is more general than (1.1) as follows:

Let $\mathrm{X}$ be subset of a normed linear space $\mathrm{E}$. A mapping $\mathrm{T}: \mathrm{X} \rightarrow \mathrm{X}$ is called an iteratively mean value contraction mapping if for every $\mathrm{x} \in \mathrm{X}$ there exist nonnegative real numbers a, such that

$$
|| \mathrm{TT}_{\lambda}\left(\mathrm{TT}_{\lambda} \mathrm{x}\right)-\mathrm{TT}_{\lambda} \mathrm{x}|| \leq \mathrm{a}|| \mathrm{TT}_{\lambda} \mathrm{x}-\mathrm{x}|| \text {, }
$$

where $0<\lambda \leq 1$ and $\mathrm{T}_{\lambda} \mathrm{x}=\lambda \mathrm{x}+(1-\lambda) \mathrm{T}_{\lambda} \mathrm{x}$ and $\mathrm{TT}_{\lambda} \mathrm{x}=\mathrm{T}(\lambda \mathrm{x}+(1-\lambda) \mathrm{T} \mathrm{x})$ holds.

The above definition is given because there are self-mappings of a subset of a normed linear space, which do not satisfy (1.1), but satisfies (1.3). An example of self-mapping for which (1.3) holds but (1.1) does not hold, is given below:

EXAMPLE 4. Let $\mathrm{T}$ be a self-mapping on $[-1,7]$ defined by

$$
\mathrm{Tx}=-\mathrm{x}, \mathrm{x}[-1,1], \mathrm{Tx}=\frac{6}{7}-\mathrm{x}, \mathrm{x} \in[1,7] \text {. }
$$




\section{MAIN THEOREMS.}

THEOREM 1. Let $\mathrm{T}$ be a self-mapping of a normed linear space $\mathrm{E}$. If

(i) T satisfies (1.1),

(ii) $\left\{x_{n}\right\}$ converges to $u \in E$ where $x_{n}=\operatorname{TT}_{\lambda} x_{n-1}(n=1,2, \ldots)$ for any $x_{0} \in E$,

(iii) $\mathrm{T}(\lambda \mathrm{u}+(1-\lambda) \mathrm{Tu})=\lambda \mathrm{Tu}+(1-\lambda) \mathrm{T}^{2} \mathrm{u}$, only for $\mathrm{u}$;

then $\mathrm{T}$ has a unique fixed point in $\mathrm{E}$.

PROOF: Let $x_{0}$ be any point in E. Define, $x_{n}=\operatorname{TT}_{\lambda} x_{n-1}(n=1,2, \ldots)$. Put $x_{0}=x$ and $x_{1}=y$ in $(1.1)$, then we have

$$
\left\|x_{1}-x_{2}\right\| \leq a_{1}\left\|x_{0}-x_{1}\right\|+a_{2}\left\|x_{0}-x_{1}\right\|+a_{3}\left\|x_{1}-x_{2}\right\|+a_{4}\left\|x_{0}-x_{2}\right\|,
$$

Again, put $x_{1}=x$ and $y=x_{0}$ in $(1.1)$. Then

$$
\left\|x_{2}-x_{1}\right\| \leq a_{1}\left\|x_{1}-x_{0}\right\|+a_{2}\left\|x_{1}-x_{2}\right\|+a_{3}\left\|x_{0}-x_{1}\right\|+a_{5}\left\|x_{0}-x_{2}\right\| .
$$

Adding (2.1) and (2.2), we obtain $\left\|x_{2}-x_{1}\right\| \leq r\left\|x_{1}-x_{0}\right\|$,

$$
\text { where } r=\frac{2 a_{1}+a_{2}+a_{3}+a_{4}+a_{5}}{2-a_{2}-a_{3}-a_{4}-a_{5}} \text { and } r<1 \text {, since } \sum_{i=1}^{5} a_{i}<1 \text {. }
$$

By induction it may be proved that $\left\|x_{n}-x_{n+1}\right\| \leq r^{n}\left\|x_{1}-x_{0}\right\|$

It may be shown by routine calculation that $\left\{x_{n}\right\}$ is a Cauchy sequence. Hence $\left\{x_{n}\right\}$ is convergent. So, by (ii), $x_{n} \rightarrow \mu \in E$, as $n \rightarrow \infty$.

Now, $\left\|\mathrm{u}-\mathrm{TT}_{\lambda} \mathrm{u}\right\| \leq\left\|\mathrm{u}-\mathrm{x}_{\mathrm{n}+1}\right\|+\left\|\mathrm{TT}_{\lambda} \mathrm{x}_{\mathrm{n}}-\mathrm{TT}_{\lambda} \mathrm{u}\right\|$

$\leq\left\|u-x_{n+1}\right\|+a_{1}\left\|x_{n}-u\right\|+a_{2}\left\|x_{n}-x_{n+1}\right\|+a_{3}\left\|u-T T_{\lambda} u\right\|+a_{4}\left\|x-T T_{\lambda} u\right\|+a_{5}\left\|u-x_{n+1}\right\|$

$\leq\left(\mathrm{a}_{3}+\mathrm{a}_{4}\right)\left\|\mathrm{u}-\mathrm{TT}_{\lambda} \mathrm{u}\right\|$, as $\mathrm{n} \rightarrow \infty$.

Therefore, $\left(1-a_{3}-a_{4}\right)|| u-T T_{\lambda} u|| \leq 0$, which implies that $u=T \lambda_{\lambda} u$, since $\sum_{i=1}^{5} a_{i}<1$. Now, $T u=T\left(T_{\lambda} u\right)=T\left(T(\lambda u+(1-\lambda) T u)=T\left(\lambda T u+(1-\lambda) T u^{2}\right)\right.$, by Therefore,

$$
\|u-T u\|=\left\|T(\lambda u+(1-\lambda) T u)-T\left(\lambda T u+(1-\lambda) T^{2} u\right)\right\| \leq r\|u-T u\| \text {, by (i). }
$$

Since $r<1,(1-r)\|u-T u\| \leq 0$ implies $T u=u i$. e. $u$ is a fixed point of $T$. Uniqueness of the fixed point follows easily. 
THEOREM 2. Let $T$ be a self-mapping of a bounded convex subset $M$ of a normed linear space $\mathrm{E}$. If for any $\mathrm{x} \in \mathrm{M}$,

(i) $\mathrm{T}$ satisfies $(1.3)$

(ii) $\left\{x_{n}\right\}$ converges to $u \in M$, whenever $\left\{x_{n}\right\}$ is convergent, where $x_{n}=T T x_{n-1}$, $(n=1,2,3, \ldots)$ for any $x_{0} \in M$.

(iii) $\operatorname{Lim}_{n \rightarrow \infty} T\left(\lambda x_{n}+(1-\lambda) T x_{n}\right)=T\left(\lambda \operatorname{Lim}_{n \rightarrow \infty} x_{n}+(1-\lambda) T \underset{n \rightarrow \infty}{\operatorname{Lim}} x_{n}\right)$

(iv) $T(\lambda u+(1-\lambda) T u)=\lambda T u+(1-\lambda) T^{2} u$, for all $u$;

then $\mathrm{T}$ has a fixed point.

PROOF: Proof is exactly similar to that of Theorem 1, so we omit it.

THEOREM 3. Let $\mathrm{E}$ be a rotund Banach space, $\mathrm{M}$ be a compact convex subset of $E$ and $T$ be a self-mapping of $M$. If $T$ is continuous and $T$ satisfies (1.2) and $\operatorname{TT}_{\lambda} \mathrm{x}=\mathrm{T}_{\lambda} \mathrm{Tx}$ for any $x \in M$, then $\mathrm{T}$ has a fixed point in $\mathrm{M}$.

PROOF: Let $x$ be any point in M. Define $f(x)=\|x-T x\|$. Since $T$ and $\|\cdot\|$ are continuous functions, therefore, $f(x)$ is also continuous. So $f(x)$ attains its minimum for some $x$ (say $x=z \in M)$.

First suppose $\|\mathrm{Tz}-\mathrm{z}\|=0$, then $\mathrm{z}$ is a fixed point of $\mathrm{T}$. Now let $\|\mathrm{T} z-z\| \neq 0$. Hence

$$
\begin{aligned}
\mathrm{f}\left(\mathrm{TT}_{\lambda} z\right)=\left\|\mathrm{TT}_{\lambda} z-\mathrm{T}\left(\mathrm{TT}_{\lambda} z\right)\right\| & =\left\|\mathrm{TT}_{\lambda} \mathrm{z}-\mathrm{TT}_{\lambda}(\mathrm{Tz})\right\| \\
& \leq\|z-\mathrm{Tz}\|<\|z-\mathrm{Tz}\| \text {, since E is rotund. } \\
& =\mathrm{f}(\mathrm{z}) \text {, which contradicts the minimality of } \mathrm{f}(\mathrm{z}) .
\end{aligned}
$$

Therefore $\|\mathrm{T}(\mathrm{z})-\mathrm{z}\|=0$ i.e. $T z=z$ is a fixed point of $\mathrm{T}$.

THEOREM 4. Let $E$ be a Banach space, $M$ be a compact convex subset of $E$, and $T$ be a continuous self-mapping of $M$. If for any $x, y(x \neq y) \in M, T$ satisfies (1.1) (where $\leq$ is replaced by $<$ ) and $\sum_{i=1}^{5} a_{i}=1$ and $\mathrm{TT}_{\lambda} \mathrm{x}=\mathrm{T}_{\lambda} \mathrm{Tx}$, then $\mathrm{T}$ has a unique fixed point in $M$.

PROOF: Proof is similar to that of Theorem 3.

\section{CONCLUDING REMARKS.}

(i) That the condition (iii) of Theorem 1 is necessary for existence of fixed point of $\mathrm{T}$ as illustrated by the following example. 
EXAMPLE 4. Let $T$ be a self-mapping on $[0,1]$ defined by $T x=1-x, x \in[0,1]$, $T(1)=0$. Here $T$ satisfies conditions (i) and (ii) of Theorem ] for $\lambda<1$, but it does not satisfy (iii) and $T$ has no fixed point in $[0,1]$.

(ii) The self-mapping $\mathrm{T}$ of Example 1 and Example 2 are non-expansive ( $\|\mathrm{Tx}-\mathrm{Ty}\| \leq\|\mathrm{x}-\mathrm{y}\|)$. Kirk [4] has proved the following fixed point theorem on non-expansive mapping:

"If $\mathrm{K}$ be a nonempty closed convex bounded subset of a reflexive Banach space $X$ and if $K$ possisses normal structure, then every non-expansive mapping from $K$ into itself has a fixed point."

The same result is also established independently by Browder [5] in a uniformly convex Banach space. There is a close connection between the theorems of Kirk and Browder. This was first noted by Goebel [6] that if $\mathrm{X}$ be a uniformly convex Banach space, then any closed convex bounded subset $\mathrm{K}$ of $\mathrm{X}$, must have normal structure.

We observe that for the existence of a fixed point of any non-expansive mapping in a Banach space, the Banach space must have a property either "uniform convexity" or "reflexivity with normal structure". Though self-mapping $\mathrm{T}$ in Example 1 and Example 2 are non-expansive, they are contractions in the sense (1.1). These mappings satisfy all the conditions of Theorem 1 . Theorem 1 explains the existence of the fixed point of the above mappings without assuming "uniform convexity" or "reflexivity with normal structure".

These examples also suggest that non-expansive mappings may be converted into contraction mappings (general process of conversion is not known). Since the study of contraction mappings is easier than non-expansive mapping, so this type conversion has some importance in fixed point theory.

ACKNOWLEDGMENT: I am thankful to Dr. S. K. Chatterjee for his kind help and continuous encouragement during the preparation of the paper. I am also thankful to the learned referee for his valuable suggestions. 


\section{REFERENCES}

[1] Kannan, R. Some Results on Fixed Points, Bull. Calcutta Math. Soc. 60 (1968) 71-76.

[2] Chatterjee, S. K. Fixed Point Theorems, C.R. Acad. Bulgare Sci. 25 (1972) 727-730.

[3] Hardy, G. and T. Rogers. A Generalization of a Fixed Point Theorem of Reich, Canad. Math. Bu11. 16 (]973) 201-206.

[4] Kirk, W. A. A Fixed Point Theorems for Mappings which do not increase Distances, Amer. Math. Month1y 72 (1965) 1004-1006.

[5] Browder, F. E. Non-Expansive Nonlinear Operators in a Banach Space, Proc. Nat. Acad. Sci. 54 (1965) 1041-1044.

[6] Goebe1, K. An Elementary Proof of the Fixed Point Theorem of Browder and Kirk, Michigan Math. J. 16 (1969) 381-383. 


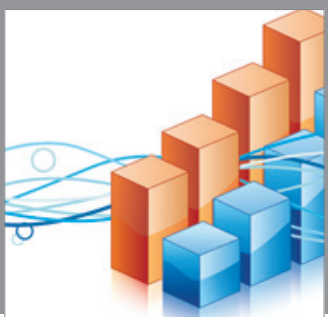

Advances in

Operations Research

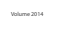

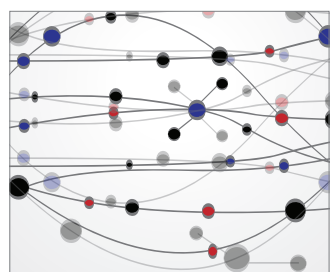

\section{The Scientific} World Journal
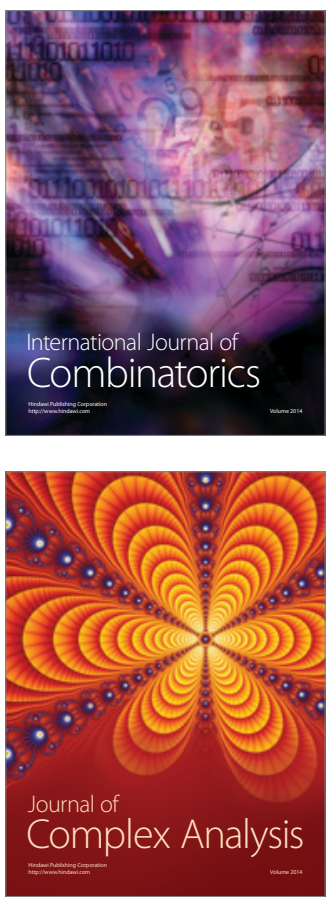

International Journal of

Mathematics and

Mathematical

Sciences
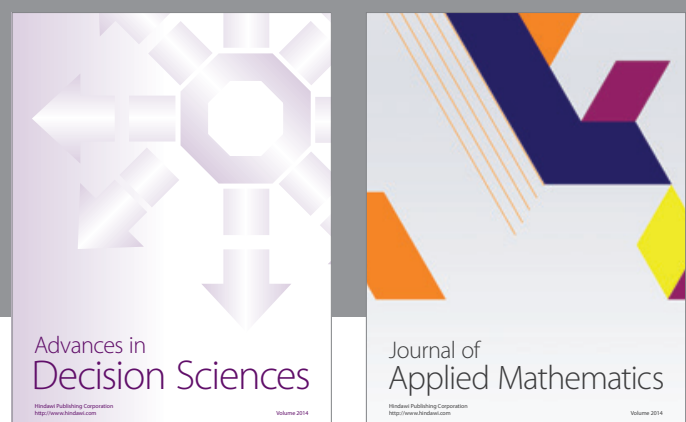

Journal of

Applied Mathematics
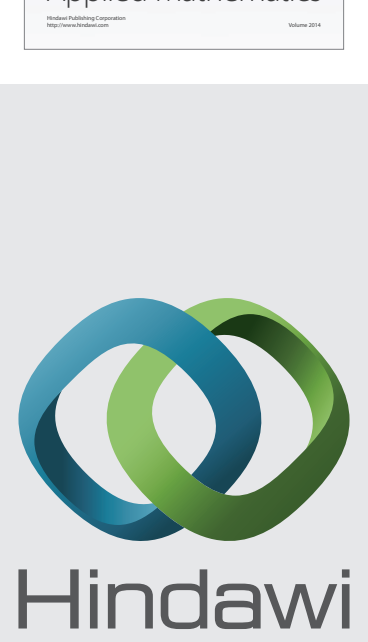

Submit your manuscripts at http://www.hindawi.com
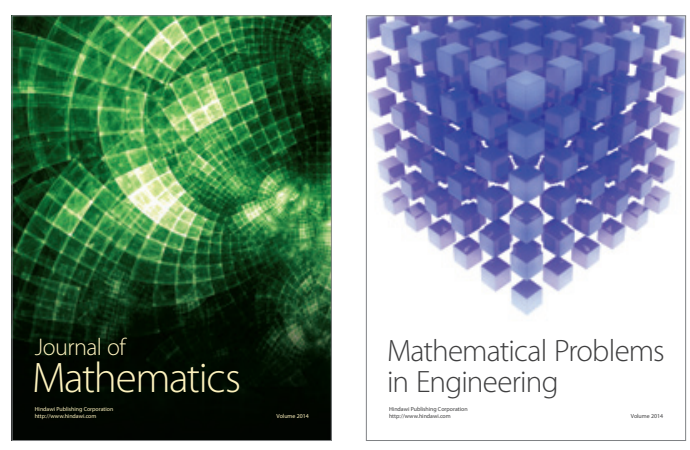

Mathematical Problems in Engineering
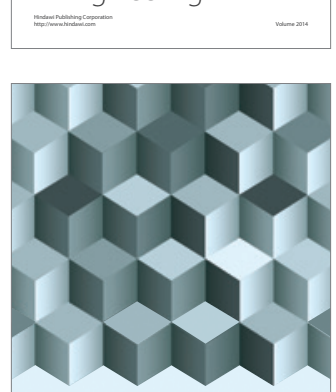

Journal of

Function Spaces
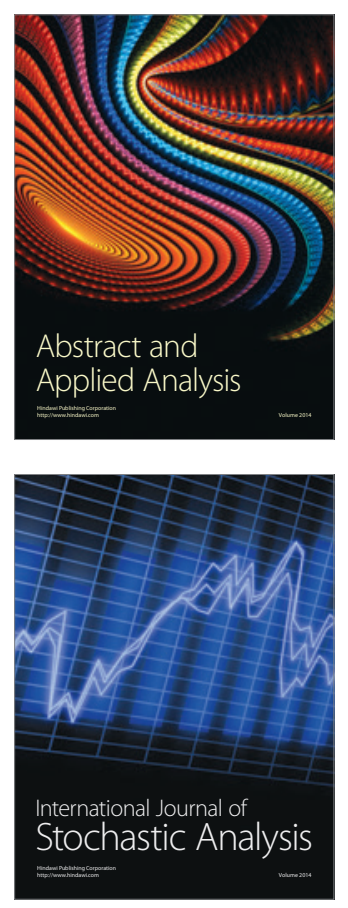

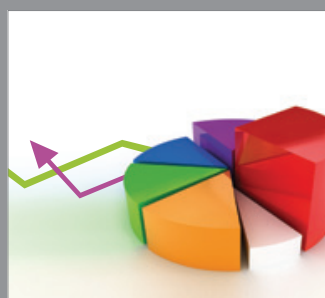

ournal of

Probability and Statistics

Promensencen
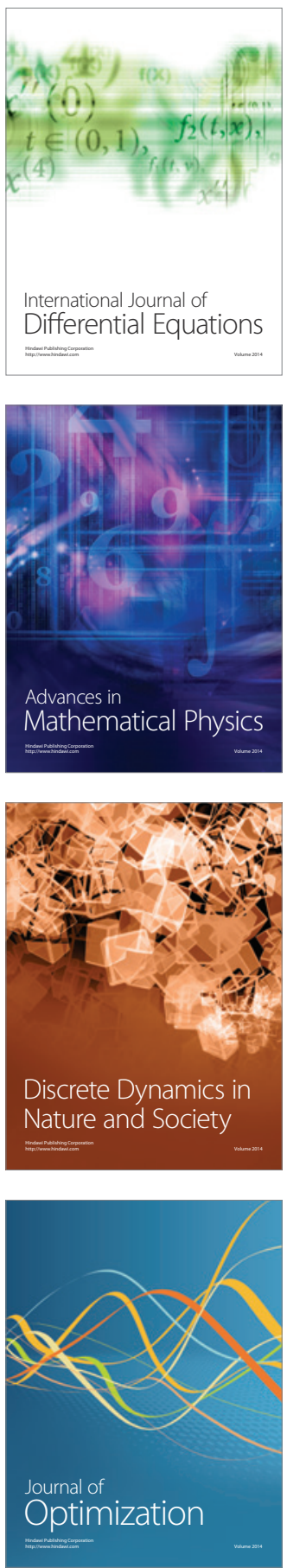